\title{
Philip Beachy
}

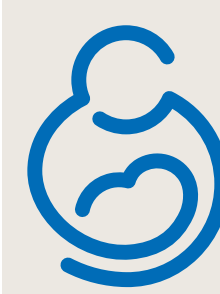

March

\section{of Dimes}

Saving babies, together

The 2008 March of Dimes Prize in Developmental Biology has been awarded jointly to Philip Beachy, who is at the Institute for Stem Cell Biology and Regenerative Medicine at Stanford University and the Department of Developmental Biology at Stanford University School of Medicine, and to Clifford Tabin, who is at the Department of Genetics at Harvard Medical School. The prize recognizes researchers whose work has contributed to our understanding of the science that underlies birth defects. Patrick Goymer talked to the winners about the influences that have shaped their scientific careers. This month we feature excerpts from a conversation with Philip Beachy; the interview with Clifford Tabin will appear in the June issue.

You've said that reading The Eighth Day of Creation got you hooked on molecular biology. What was the appeal?

I was at a small liberal arts college as an undergraduate from 1975-1979. There really wasn't much in the way of modern genetics and molecular biology being taught so to read an account of the early days of molecular biology, not just the findings but the pace and excitement, the way ideas flowed from other ideas, was incredibly exciting. So that was my first real exposure ... it communicated very well how science is a living thing done by people, people who are very active intellectually, and that was what caught my eye....

How did you come to focus on hedgehog? My postgraduate career didn't immediately focus on hedgehog - I was focused on Drosophila homeotic genes and hedgehog sort of came through the backdoor because I was looking for enhancers that represent targets for homeotic genes. One of the things we found was an expression pattern that turned out not to be a mutation but just a reporter of expression. We looked at in situ hybridization to polytene chromosomes - the way that things were done back then before genome sequencing - and the thing turned out to map near the known genetic locus of hedgehog. The hedgehog gene had not yet been isolated, and when I moved to Johns Hopkins University my lab grew significantly and I was able to devote resources to hedgehog, which gradually waxed as homeotics waned after we published the isolation and characterization of the Drosophila hedgehog gene in 1992.
How important is it that students today understand the principles behind such early genomics work, even if the techniques themselves are obsolete?

I think it's important in the sense of having a real appreciation of how we got where we are. I was a student in Dave Hogness's lab in Stanford, which is where the foundations for modern genomics were established - the idea of isolating overlapping DNA segments from libraries through screening and then building a contiguous stretch of DNA using the polytene chromosomes to see where you're going, and beyond that to move in a directed manner to know the locations of interesting developmental genes. [...] Having grown up in that environment I think it is very important for students to have an appreciation of how we got where we are, but in practical terms I would have to admit that I'm not sure they really need to know....

Which other scientists have had the greatest influence on your career?

I was really inspired by Nüsslein-Volhard and Wieschaus, and also by Ed Lewis. These were folks who brought a systematic approach to development and used the best tool available then - genetics - in what was the first application of functional genomics. People now talk about functional genomics as a new invention, but what they did was to systematically examine the functional basis for the establishment of pattern in the developing fly. The way they were able to abstract from the huge number of mutants - just looking at the dead embryos they could infer an underlying process and logic - was very compelling. I was also influenced in general by the department I was in as a grad student, the biochemistry department, where there was a real emphasis on mechanism and getting to a molecular level in how things work.

You decided not to go into medicine a close decision between science and medicine - do you now find it satisfying that your career has come full circle and that there are medical implications of your work?

Yes, I really do enjoy that. When I was thinking about it as a college student my concept of medicine was clinical medicine. [...] I scrubbed in for surgeries every day for a month and a half. Living human anatomy is amazing and the colours are beautiful, but I realised that surgeons do very similar things from one patient to the next. I didn't have a concept of academic medicine where you're trying to learn more about a disease, so for me there was a difference between medicine and science. [...] There are certainly people whose work is far more basic and those that are far more clinical but there's a meeting ground and I do like the fact that hedgehog finds itself at that intersection.

You've moved to a stem cell institute. What predictions do you have for stem cell biology? The pace in this area is really incredible and just one example of how quickly things can change is provided by findings from Yamanaka who was able to reprogramme skin cells to pluripotency, like ES [embryonic stem] cells. [...] The reason I bring that up is that in the US, which is rather unique in the developed world for its legal treatment of stem cell research (although, incidentally, I think that's likely to change shortly after the next election, or at least I hope so!), the ability to reprogramme somatic cells shifts the whole debate to a different level and changes the ethical underpinnings of the issue. If you can do this with patients then you don't need to rederive or make ES lines.

[...] It's hard to predict where stem cell biology will lead in terms of medical advances. I think there will be some significant advances, but to me it's not clear whether they will necessarily come from cell therapy by manipulating cells ex vivo and reintroducing them. Another route would be to manipulate cells in vivo - once we know enough about stem cells and how they're regulated we may be able to reprogramme cells in desirable directions in vivo. 